\title{
Research Report on Learning Needs Analysis and Feedback on CBI Nursing English Course
}

\author{
Lei $\mathrm{Xu}^{1, *}$ \\ ${ }^{1}$ Department of Basics, Sichuan Nursing Vocational College, Deyang, Sichuan 618000, China \\ *Corresponding author.Email: xulei@cnsnvc.edu.cn
}

\begin{abstract}
112 Midwifery sophomores from the Nursing Department in a vocational college in Sichuan Province, China were chosen as the research subjects. Through combined research methods: questionnaire survey, classroom observation and semi-structured interview, students' learning needs, status quo, problems and feedback in Nursing English course were investigated. Using SPSS17.0 as the research tool, 4 factors were drawn to analyze students' learning motives, cognition about CBI model, feedback and evaluation, and real experience of CBI. Via open-ended questions and interviews, students' learning problems in the course, gains and suggestions for improvement were collected for exploring how to design Nursing English course, how to reform learning and teaching practice by virtue of CBI, so as to improve students' learning interest and motivation, enhance English communicative competence between nurse and patients and cultivate "double qualified" professional nursing talents for the society thereafter.
\end{abstract}

Keywords: Nursing English; CBI model; Needs analysis; Teaching feedback

\section{INTRODUCTION}

Vocational college students generally have a weak foundation in English. Based on College English study (EGP: English for General Purposes) in the freshman year, to carry out professional English instruction (ESP: English for Specific Purposes) in the sophomore year is both a challenge and an opportunity for many students. The challenge is how to learn nursing content knowledge in English, while the opportunity is that students with good learning effect will be able to pass Medical English Test System (METs), transfer to a better university through exams and get a better job and promotion opportunity in the near future, or to participate in international exchange programs, become competent for foreign-related nursing work, and meet high-level employment requirements. CBI (Content-based Instruction), which originated from the "Immersion Program" in Montreal, Canada in the 1960s, was introduced to China in the 1990s and achieved EFL aim through thematic or subject matter instruction[1]. During its development, CBI has gradually formed three modes or variants, i.e. theme-based instruction, sheltered subject-matter instruction, and adjunct instruction[2]. Since the 21st century, major universities across the country have been actively carrying out empirical study on "Foreign Language Plus Major" under the guidance of CBI model, and have made some achievements[3][4][5]. Through organic integration of English and content knowledge, CBI can mobilize students' learning interest and motivation, improve learning enthusiasm, initiative and creativity, and therefore effectively improve teaching efficiency and effectiveness. The purpose of this research is to investigate the similarities and differences in learning motivation, cognition, attitude and needs for Nursing English course among the students in different levels majoring in midwifery in the Nursing Department, so as to provide references and suggestions for schools to further improve curriculum design, for teachers to improve teaching methods, for students to improve learning strategies, and ultimately achieve the goal of improving the overall learning effect of the course.

\section{RESEARCH SUBJECTS, METHODS AND TOOLS}

The subjects of this research are 112 sophomore students in the "low-level" and "high-level" classes of Midwifery major in a medical nursing vocational college. All of the students accepted formal English instruction over 10 years, starting from elementary school. "high-level" students were recruited through the College Entrance Examination, the overall English foundation is better, and individual differences are smaller; after a 3-year vocational secondary school study, "low-level" students directly enrolled in the counterpart college for further study, and the overall English learning foundation is poorer, and individual differences are bigger. A five-point Likert-scale questionnaire survey was used as the major research method. In order to ensure its reliability, the questionnaire was filled out anonymously. The researcher has fully explained the requirements of the questionnaire before handing it out, to ensure that questions and concerns of the students have been excluded and the received data is true and valid. A total of 112 questionnaires were issued and 105 valid questionnaires were returned, with a recovery 
rate of $93.75 \%$. Combining classroom observation and semi-structured interviews, the reliability and validity of the research were guaranteed through "Triangulation". SPSS17.0 was used as the research tool to process, analyze and summarize the questionnaire data.

\section{RESEARCH RESULTS AND DATA ANALYSIS}

Through KMO test and Bartley sphere test, $\mathrm{KMO}=0.874>0.8 \quad$ (Sig.000), which proves that the questionnaire is highly valid and can be used for Factor Analysis. According to the internal logic among questions and combined with the analysis of Scree Plot, 4 factors are obtained: 1. Students' Learning Motivation 2. Students'
Cognition of CBI 3. CBI Feedback and Evaluation 4 Students' Real Experience. Through Reliability Test, Cronbach's alpha $=0.899$, which shows that the questionnaire is highly reliable and the data is persuasive. Looking at the data results of Factor Analysis, it can be seen that the mean of the factor "Students' Learning Motivation" is the highest (Mean=3.75, Std.=0.59), and the mean of the factor "CBI Feedback and Evaluation" is the lowest (Mean=3.27, Std. =0.44), the means of the factor "Students' Cognition of CBI" and "Students' Real Experience" are between 3.5 and 3.6. Generally speaking, students have a good learning motivation and experience; they accept, recognize and support the CBI model (See Table 1). After Independent Samples T-test, $\mathrm{P}>0.05$, there is no significant difference in the means of the two groups of students in the 4 dimensions.

Table 1. Statistical Data in 4 Factors

\begin{tabular}{llll}
\hline & $\mathrm{N}$ & Mean & Std. Deviation \\
\hline 1.Students' Learning Motivation & 105 & 3.7476 & .58567 \\
2.Students' Cognition of CBI & 105 & 3.6038 & .58703 \\
3.CBI Feedback and Evaluation & 105 & 3.2738 & .43788 \\
4.Students' Real Experience & 105 & 3.4667 & .58419 \\
Valid N (listwise) & 105 & & \\
\hline
\end{tabular}

Through further dimensional reduction, the author carried out further descriptive statistical data analysis for each dimension, and obtained analytical results and conclusions of specific problems on each factor.

\subsection{Students' Learning Motivation}

Students believe that learning Nursing English can deepen their professional knowledge and learn to use simple nursing-contextual oral English to communicate with foreign patients $(M e a n=4.04$, Std. $=0.73$ ); meanwhile, they think learning Nursing English is very beneficial for their future work (Mean=4.04, Std. =0.75), whose means are the highest. I am very interested in Nursing English (Mean=3.50, Std.=0.78); I will take the opportunity to take
METs test, work or study abroad in the future (Mean=3.55, Std.=0.87), with the lowest means. Learning Nursing English can help learn and understand the knowledge of other nursing-related courses better (Mean=3.63, Std.=0.84); setting up Nursing English course can motivate students to consolidate English language foundation (Mean=3.73, Std. =0.70), whose means are relatively high On the whole, in order to meet work needs, the strongest learning motive for students is to communicate with patients in English; they have weaker desires to study for getting certificates, upgrading to a better university or providing opportunities for going abroad through learning the course; students have a strong motivation in light of consolidating basic English skills and understanding subject content knowledge better through the course (See Table 2).

Table 2. Statistical Data in Students' Learning Motivation

\begin{tabular}{|c|c|c|c|}
\hline & $\mathrm{N}$ & Mean & $\begin{array}{l}\text { Std. } \\
\text { Deviation }\end{array}$ \\
\hline 1. I am very interested in Nursing English & 105 & 3.50 & .774 \\
\hline 2. I will take the opportunity to take METs test, work or study abroad in the future & 105 & 3.55 & .866 \\
\hline 3. Nursing English course is beneficial for my future work & 105 & 4.04 & .746 \\
\hline $\begin{array}{l}\text { 4. Learning Nursing English can deepen professional knowledge and help to use simple } \\
\text { nursing-contextual oral English to communicate with foreign patients }\end{array}$ & 105 & 4.04 & .733 \\
\hline $\begin{array}{l}\text { 5. Learning Nursing English can help learn and understand the knowledge of other } \\
\text { nursing-related courses better }\end{array}$ & 105 & 3.63 & .835 \\
\hline $\begin{array}{l}\text { 6. Setting up Nursing English course can motivate students to consolidate English language } \\
\text { foundation }\end{array}$ & 105 & 3.73 & 697 \\
\hline Valid N (listwise) & 105 & & \\
\hline
\end{tabular}




\subsection{Students' Cognition of CBI}

"Nursing English Learning Supplementary Materials"The Chinese translation handbook of the English textbook provided by the teacher can help them learn Nursing English course better (Mean=3.89, Std.=0.64); learning Nursing English can facilitate students to learn, understand and use professional English to make daily communication and interaction with patients in medical care work (Mean=3.90, Std.=0.65); offering Nursing English course can meet the demands of "learning to use professional English to serve future work" (Mean=3.84, Std.=0.70), whose means are higher. In Nursing English classes, students accept the teacher to use English exclusively as the instruction language (Mean=3.23, Std.=0.95); students understand and accept original Nursing English textbook (Mean=3.17, Std.=0.89), whose means are lower. The data shows students consider original CBI English textbook and English Immersion Teaching Method are a little bit difficult for them to learn; Chinese-version supplementary materials are helpful for understanding and mastery of the knowledge; CBI course serves students to complete foreign-related nurse-patient communication and professional work (See Table 3).

Table 3. Statistical Data in Students' Cognition of CBI

\begin{tabular}{|c|c|c|c|}
\hline & $\mathrm{N}$ & Mean & $\begin{array}{l}\text { Std. } \\
\text { Deviation }\end{array}$ \\
\hline 1. Students' acceptance of using English exclusively & 105 & 3.23 & .953 \\
\hline 2. Students' understand and accept authentic textbook & 105 & 3.17 & .893 \\
\hline 3. Nursing English learning supplementary materials are beneficial & 105 & 3.89 & .640 \\
\hline $\begin{array}{l}\text { 4. Learning Nursing English can facilitate students to learn, understand and use } \\
\text { professional English to make daily communication and interaction with patients in medical }\end{array}$ & 105 & 3.90 & .649 \\
\hline $\begin{array}{l}\text { 5. Offering Nursing English course can meet the demands of learning to use professional } \\
\text { English to serve future work }\end{array}$ & 105 & 3.84 & .695 \\
\hline Valid N (listwise) & 105 & & \\
\hline
\end{tabular}

\subsection{CBI Feedback and Evaluation}

In College English classes, teachers mainly explain language knowledge such as vocabulary and grammar, and students are passive learners (Mean $=3.17$, Std. $=0.83$ ); the content of College English textbooks is outdated and cannot meet the actual needs of students (Mean=2.86, Std.=0.85). Actually, students do not agree that College English textbooks are out-of-date, nor do they strongly recognize themselves as passive recipients of knowledge, indicating that students do not think traditional College
English teaching models are far from good, and the need for urgent change is not strong. In response to the question "With existing knowledge, are you capable of learning Nursing English course?" Mean=2.92, Std.=0.97, suggesting that students do not believe they are fully capable of learning this course; on the contrary, students suppose that English teacher is competent enough to teach CBI professional English course (Mean=4.14, Std.=0.86), indicating that the capability of English teachers to assume CBI course is very recognized (See Table 4).

Table 4. Statistical Data in CBI Feedback and Evaluation

\begin{tabular}{|c|c|c|c|}
\hline & $\mathrm{N}$ & Mean & $\begin{array}{l}\text { Std. } \\
\text { Deviation }\end{array}$ \\
\hline 1. In College English course, students are passive learners & 105 & 3.17 & .826 \\
\hline $\begin{array}{l}\text { 2. The content of College English textbooks is outdated and cannot meet the actual needs } \\
\text { of students }\end{array}$ & 105 & 2.86 & .848 \\
\hline 3. With existing knowledge, I am capable of learning Nursing English course & 105 & 2.92 & .968 \\
\hline 4. My English teacher is competent enough to teach CBI professional English course & 105 & 4.14 & .860 \\
\hline Valid N (listwise) & 105 & & \\
\hline
\end{tabular}

\subsection{Students' Real Experience}

In Nursing English classes, students have many activities and opportunities to simulate daily communication between nurse and patients in English (Mean=3.90, Std.=0.63). Students simulate real-life nurse-and-patient interaction through Role-play, and their English listening and speaking skills have been intensively trained in the meantime; In Nursing English classes, students play the main role of the class, class activities and teaching materials can meet the needs of actual work in the future (Mean=3.56, Std.=0.72); in Nursing English classes, the classroom atmosphere is very relaxed, students actively answer questions and the teacher-student interaction is quite frequent $($ Mean $=3.58$, Std. $=0.86)$; students can effectively integrate English knowledge acquired in Nursing English course with professional content knowledge acquired in other nursing courses (Mean=3.57, Std. $=0.78$ ). The means of these 3 items are not very high, 
suggesting that students' participation in the classroom is not enough, classroom silence occurs from time to time, and the organic combination of English and content knowledge needs to be strengthened. The interesting point is that the author finds that although "low-level" students have a weaker English foundation, they are more proactive, better prepared, and more expressive in pair and group video presentation, and the works presented are more creative and with better quality. It is worth noting that, in general, students are not very interested in learning CBI course (Mean=2.71, Std.=1.28), and the mean of "high-level" students (Mean=3.17) is significantly higher than that of "low-level" counterparts (Mean=2.42), Sig.000. This is inseparable from factors such as the difference between students' English and subject foundation, learning motivation, learning habits, learning strategies and class atmosphere etc (See Table 5).

Table 5. Statistical Data in Students' Real Experience

\begin{tabular}{|c|c|c|c|}
\hline & $\mathrm{N}$ & Mean & $\begin{array}{l}\text { Std. } \\
\text { Deviation }\end{array}$ \\
\hline $\begin{array}{l}\text { 1. In Nursing English classes, students play the main role of the class, class activities and } \\
\text { teaching materials can meet the needs of actual work in the future }\end{array}$ & 105 & 3.56 & .720 \\
\hline $\begin{array}{l}\text { 2. In Nursing English classes, students have many activities and opportunities to simulate } \\
\text { daily communication between nurses and patients in English }\end{array}$ & 105 & 3.90 & .628 \\
\hline $\begin{array}{l}\text { 3. In Nursing English classes, the classroom atmosphere is very relaxed, students actively } \\
\text { answer questions and the teacher-student interaction is very frequent }\end{array}$ & 105 & 3.58 & .864 \\
\hline 4. In Nursing English classes, I feel learning is interesting & 105 & 2.71 & 1.284 \\
\hline $\begin{array}{l}\text { 5. Students can effectively integrate English knowledge acquired in Nursing English course } \\
\text { with professional content knowledge acquired in other nursing courses }\end{array}$ & 105 & 3.57 & .783 \\
\hline Valid N (listwise) & 105 & & \\
\hline
\end{tabular}

For the question "How much percentage can you understand in Nursing English classes?", 25\% 50\% and $50 \% \sim 75 \%$ account for the largest proportion, with $35.24 \%$ and $37.14 \%$ respectively; $20.90 \%$ of students understand $0 \% \sim 25 \%$; only $5.71 \%$ of students choose $75 \% \sim 100 \%$. The data shows that more than $2 / 3$ of students can understand the main teaching content of CBI course; $1 / 5$ of students have problems in learning; a very small number of students can well understand almost all the content of the course. Therefore, the data implies that content in CBI course is moderately difficult and can be understood and accepted well by most students.

"What do you like to learn most in Nursing English classes?", nearly $40 \%$ of students prefer to learn nursing professional knowledge; listening, speaking, vocabulary and phrases accounts for about $20 \%$ each; reading only makes up less than 10\%; No classmates choose writing. The data shows that students pay more attention to the learning of subject content knowledge in CBI course, and their interest in learning English linguistic knowledge mainly focuses on applied knowledge and skills (listening, speaking, vocabulary and phrases) which can be used for nurse-patient communication, motivation for learning test-oriented knowledge and skills (reading and writing) is not strong.

"In Nursing English classes, what do you think the teacher should focus on teaching?" and "What do you think students should focus on learning?", the data manifests the same trend. More than $1 / 3$ of students put learning nursing professional knowledge in the priority; speaking, vocabulary and phrases account for about $1 / 4$ of the proportion each; listening, reading and writing combined together is less than $1 / 10$. As is shown, students consider that learning of subject content is the first of the first things, oral communicative competence based on vocabulary acquisition is also highly valued by students, and test-oriented English skills are paid the least attention. "In the final examination of Nursing English course, what do you think should be focused on examining?", nursing professional knowledge and vocabulary accounts for $1 / 3$ of the ratio each, indicating that students pay the most attention to learning of subject content and mastery of English foundation knowledge. Reading and speaking each makes up $15 \%$ or so, listening only accounts for less than $3 \%$, and once again no one chooses writing. Combined with interviews and classroom observations, the author believes that assessment of the latter 4 abilities is a certain kind of difficulty for the majority of students, which coincides with the current situation of students' overall weak English foundation.

\section{PROBLEMS, FEEDBACK AND RECTIFICATION MEASURES}

Through the design of open-ended questions and in-depth interviews, the author collected some relating problems, feedback and suggestions regarding how to improve the course.

\subsection{Problems in Nursing English Course}

At teachers' level, English teachers generally lack adequate accumulation of professional content knowledge, neither in depth nor in breadth; the instruction of professional knowledge is enough, and the expansibility of knowledge needs to be improved. At students' level, students have a good grasp of professional content knowledge, but weak English linguistic foundation makes 
it difficult for them to fully understand original English professional textbook and accept English-immersion instruction. Meanwhile, they have a poor mastery of technical terms and jargon. In terms of teaching methods, the teacher relies too much on the content of textbook, the novelty and diversity of teaching activities are insufficient; in terms of learning methods, students lack the consciousness of independent exploration and the awareness of learning autonomy, and are reluctant to cooperate with the teacher in conducting "Brainstorming", "Topic discussion", "Role-play", "Classroom presentation" and other classroom interactive activities and exercises, "Negative, Passive, Silent" learning occurs occasionally.

\subsection{Major Learning Difficulties and Obstacles in the Learning Process of Nursing English Course}

In addition to professional terminology and jargon, what students mentioned most is lack of motivation for learning. Due to a lack of career plan for studying abroad or engaging in high-level foreign-related nursing occupation which needs English communicative competence as a prerequisite in the future, students' learning expectations for Nursing English course often just stay at passing the final exam, in short of higher-level learning needs.

\subsection{Major Gains in the Learning Process of Nursing English Course}

Students claim that while English linguistic skills (especially listening and speaking) are improved, nursing professional content knowledge has been enhanced and strengthened. By comparing the similarities and differences between domestic and foreign nursing apparatus and equipment, operating specifications, nurse-patient communication strategies, and crisis management measures, students become more familiar with international nursing standard operating procedures, capable of recognizing, distinguishing and filling in various kinds of English nursing documents and charts, and also master the skill of writing nursing records and documents in English, Besides, they have learned how to communicate effectively and interact efficiently between nurse and patients, along with how to avoid nurse-patient disputes or crisis.

\subsection{Help of Nursing English Course in Further Studies, Internship and Employment}

The study of the course can help students prepare for tests, better equip themselves for the Medical English Test System (METS), and increase the passing rate; the training and improvement of professional English listening, speaking, reading, writing and translation skills can help students pass upgrading exams which can offer them the opportunity to transfer to a better university for further study and engage in foreign nursing affairs with favorable conditions.

\subsection{Suggestions Put Forward by Students}

In order to improve the teaching effect of Nursing English course, students suggest that English teacher should not use English exclusively to teach. Appropriate combination of Chinese and English instruction can help students better understand subject professional knowledge, master occupational skills, clarify professional English concepts and terminology, thereby increasing self-efficacy in learning and becoming more concentrated in the class without easy distraction, so as to avoid the occurrence of "Swallowing all the knowledge without seeking a thorough digestion" in learning.

\section{CONCLUSION}

It is urgent to deepen teaching reforms for Chinese vocational education. How to create an interesting, efficient and interactive Nursing English instruction model needs to be further studied. Combining WeChat applets with cloud platforms to build a teaching resource repository, integrate resource database, discussion platform, and exercise interactive platform together to ameliorate the construction of curriculum system[6][7]. The research shows that it is feasible to conduct CBI course in nursing vocational colleges in China. The concern is how much proportion of language to content should be assigned in the integration process and which is the optimal form or mode to conduct the instruction according to students' distinctive language and content foundations. Through in-depth integration of English and professional content courses, students' learning interest and motivation can be increased to meet their requirements of upgrading in domestic university, graduation, job hunting, and overseas study etc. in the new era. With the combination of school's infrastructure conditions and students' academic foundations, it is recommended that vocational colleges should formulate appropriate CBI curriculum designs, arrange reasonable teaching plans, and integrate modern Internet multimedia technology to carry out curriculum teaching reforms to promote curriculum construction and development, so as to satisfy the urgent needs of improving professional English ability for vocational college students. Through "Reform promotes teaching, and teaching promotes learning", international compound personnel who can use English to deal with major-related problems in occupation will be cultivated and meet the demands of fostering professional technical talents in the modernization for the country and society. 


\section{ACKNOWLEDGMENT}

Funding Project of Sichuan Nursing Vocational College in 2021 (2021RWSY63)

\section{REFERENCES}

[1] Chang Junyue. A Study of CBI Reform for English Majors in the Lower Division in the Chinese Context [M]. Beijing: Peking University Press, 2015. (In Chinese)

[2] Brinton, D.M., Snow,M.A. \& Wesche,M.B. Content-based Second Language Instruction [M]. Ann Arbor: The University of Michigan Press,2003.

[3] Cao Peisheng. An experimental study on the effectiveness of CBI theme-based teaching mode in college English teaching [J]. Technology Enhanced Foreign Language Education, 2012(03): 51-55. (In Chinese)
[4] Lei Chunlin. Content-based instruction and its implications for compound foreign language teaching in China-Taking business English teaching as an example [J]. Technology Enhanced Foreign Language Education, 2006, (03): 32-38. (In Chinese)

[5] Yuan Pinghua. A Study on CBI in the Chinese College English Context [M]. Nanchang: Social Sciences Academic Press, 2014. (In Chinese)

[6] Wang Meixiang, Luo Yu, Chen Ran, Cai Mengyi, Sun Xiaoming, Sun Xiaoning. Analysis on the nursing students' learning needs of Internet situational teaching method for nursing spoken English in University of Chinese Medicine [J]. Chinese Medicine Modern Distance Education of China, 2021,19(10):1-3. (In Chinese)

[7] Wang Xue, Huang Wanxia, Ge Lu, Peng Huijiao, Zheng Changhua, Peng Xia. Research on the application of CBI in the construction of vocational nursing English databases [J]. Modern Vocational Education, 2021(19): 88-89. (In Chinese) 